\title{
Aisthesis
}

Firenze University Press

www.fupress.com/aisthesis

OPEN ACCESS

Citation: S. Velotti (2021) A New Image of Humanity? A Transcendental in the Making. Aisthesis 14(2): 5-15. doi: 10.36253/Aisthesis-13204

Copyright: (c) 2021 S. Velotti. This is an open access, peer-reviewed article published by Firenze University Press (http://www.fupress.com/aisthesis) and distributed under the terms of the Creative Commons Attribution License, which permits unrestricted use, distribution, and reproduction in any medium, provided the original author and source are credited.

Data Availability Statement: All relevant data are within the paper and its Supporting Information files.

Competing Interests: The authors have declared that no competing interests exist.

\section{A New Image of Humanity? A Transcendental in the Making}

\author{
Stefano Velotti \\ Sapienza Università di Roma (Italy) \\ stefano.velotti@uniroma1.it
}

\begin{abstract}
If it is true that at the core of the Enlightenment project was an attempt to discover a new definition of human nature itself, there is no doubt that for a long time, and today more than ever, there is a similar urgency to find a different vision of humanity, since the prevailing one - heir of the Enlightenment - is perceived from many sides as in need of a profound revision, if not catastrophic. if we are living in the ruins of modernity, we should neither attempt to embalm them, nor to raze them to the ground. This article maintains that Kant's work on the reflecting judgment (along with a productive reinterpretation of notions such as "finality», «exemplarity», «heautonomy») can offer precious resources to reshape that image of humanity that we feel is now inadequate in the face of the complexity of our forms of life, without the need to abandon ourselves to old and new longings for the absolute.
\end{abstract}

Keywords: Reflecting Judgment, Finality, Exemplarity, Heautonomy, Ontological Turn.

\section{A NEW IMAGE OF HUMANITY?}

The forces and aspirations that find expression in our affluent societies today are manifold, not to mention those that elsewhere find no space to make themselves heard, because they are far removed from the interests that occupy the global politicaleconomic establishment. Some of these forces - emotions, frustrations, longings, desires, worldviews - find access even in academic research, received and articulated in philosophical, anthropological, sociological discourses. In the background of the many crises we are experiencing - ecological, economic, moral, political - I believe there is a greater struggle, whose stake is the very image of humanity. If it is true that «at the core of the "Enlightenment project" was an attempt to discover a new definition of nothing less than human nature itself», (Pagden [2013]: 21-22], there is no doubt that for a long time, and today more than ever, there is a similar urgency to find a different vision of humanity, since the prevailing one - heir 
of the Enlightenment - is perceived from many sides as inadequate, partial, unsuccessful, in need of a profound revision: all the "post-something" (not only the now worn out postmodern, but the postsecular, the posthuman, the postcolonial, the postcritical) that abound in academic discourse or public conversation are signs of this travail. These "post conditions" are all aimed at modifying, revising, or even rejecting the Enlightenment legacy that is integral to our concept of modernity. Leaving aside the more reactionary and conservative critiques of the Enlightenment, which have accompanied it since its beginnings (cf. Pagden [2013]: 373-417), and so also its current triumphalist apologies (e.g. Pinker [2018]), it nevertheless seems that "the age of critique" has lost its appeal for many, (Latour [2004]), and thus the very recourse to judgment is viewed with impatience, in favor of other practices (cf. Deleuze [1983]), sometimes even within a practice that is defined by the very exercise of judgment such as art criticism (Elkins [2003]).

Apart from the fact that modernity, and the Enlightenment itself, are not at all as monolithic and uniform as some would like to present them, it might also be true that «we have never been modern» (Latour [1991]), - if we mean on the one hand that the so-called modernity is imbued with archaic elements, and, on the other, that its most triumphalist proclamations do not find correspondence in its actual practices -, but then we should also affirm the inverse, namely that «we have never been non-modern", in the sense that every culture, even the cultures that we like to see as more «enchanted» and «tribal», are not at all compact and sealed in "the other of reason», and host within them critical reflections, skepticism, questions, pluralisms, non-uniform forms of life. The European Enlightenment itself is unthinkable without taking into account the encounter/clash with different cultures ${ }^{1}$. Often, even in those most

1 The ontological pluralism assumed by the proponents of the "ontological turn» has been harshly criticized by Graeber in several respects, not least of which is that it is itself a form of generalized aprioristic categorization with inclined to see modernity unilaterally as a single block of totalizing, scientistic, Eurocentric, colonial, capitalist, patriarchal thought, blind and violent towards the richness of the pluralism of possible forms of life and alternatives to «ours» - at times the thought emerges that this same critique of modernity inherited from the Enlightenment is inevitably its heir. These efforts to overcome the "totalizing» perspective of modernity are addressed to the recognition of an epistemological and ontological pluralism ${ }^{2}$, in an attempt to depower, limit or at least reformulate the "autonomy» of the modern subject-individual and his world.

On the more strictly philosophical side, even more daring attempts are multiplying, aiming at unhinging the very "correlation» of human subjects with reality, in order to ensure its autonomy, trying to bypass any human footprint. As if the just (and belated) concern for the traces left on the world by the richest part of humanity - including those at the origin of the climate and ecological crisis we are witnessing - should be translated into metaphysical terms, exalting the autonomy of the non-human reality, its literal absoluteness. One could hypothesize that this fascination for objects, for absolute contingency, for what does not depend in any way on us - as if it had never been recognized by anyone in the past - is motivated by a sort of compensation, sub spe-

undesirable consequences: "The problem with cultural relativism is that it puts people in boxes not of their own making. [...]. Ontology2 [an ontology resulting from taking empirical, cultural concepts as constitutive as Kantian categories] only replaces a deeper box. Some people like deep boxes. There seems to be every reason to believe that those with whom Viveiros de Castro works, those with whom he fights for the rights to "ontological selfdetermination", are among them. But by the same token, one must respect the desires of those who wish their boxes to be shallower, or who do not wish to be put in any kind of box» (Graeber [2015]: 34). For a view of the Enlightenment as indebted to Europeans' encounters with «other» cultures see now Graeber, Wengrow (2021).

${ }^{2}$ See Consigliere (2020). On the limits and ambiguities of the so-called «ontological turn» in anthropology from a philosophical point of view see Leghissa (2021). 
cie aeternitatis, for our cumbersome presence. A sort of homeopathic cure: curing the anguish of disappearing from the earth's crust by erasing our traces in the skies of speculation. The threat (for our species) of a world without us, is anticipated - in a way not devoid of contradictions - in exercises of thought that would like to free the real, of which they speak and with which they relate, from any correlation with human subjects, including themselves.

Of course, these are only impressionistic generalizations, and every single proposal should be evaluated with due attention. But if it is difficult to orient oneself in this maze of theories, it is also difficult not to think of a solidarity between the most superficial reconsideration of animism and panpsychism, of metamorphosis and «becoming other» - often associated with the exaltation of immersivity and interactivity promised in every press release of exhibitions and artistic performances -, and the anxiety for a new absolute, that of the real and of objects, animate and inanimate, finally freed from our (conceptual) grasps. Remaining on this impressionistic level of generality, we must reiterate that the needs from which these theories and reflections emerge are understandable and legitimate, but it remains to be decided whether the answers have so far found convincing formulations.

These very general references to our cultural landscape may seem disproportionate to the task we have set ourselves in this article: to re-examine some of the junctures of critical reflection, of Kantian origin, on the nature of the faculty of judgment in relation to finality, or conformity to purposes (Zweckmässigkeit). But the very fact that the philosophical-cultural currents just mentioned often have Kantian thought as their main polemical target made it opportune to recall them.

Outside the large circle of his scholars, in fact, Kant is now from time to time casually named as the greatest representative of an Enlightenment blinded by the myth of reason ${ }^{3}$, of a Eurocen-

\footnotetext{
3 "The thesis that Kantian philosophy has removed "the other of reason" turns out to be a weak legend», Fabrizio
}

tric universalism (and therefore in reality tribal and colonial) $)^{4}$, of a monolithic and self-confident modernity, or instead as the founder of a postmodern mentality, constructivist to the extreme of idealism, disrespectful of the hardness and independence of reality. In the field of aesthetic reflection, then, as if by a conditioned reflex worthy of a Flaubertian dictionary of received ideas, he is immediately associated with the stigma of "disinterested contemplation», as if this were something that would not even be worth trying to understand, simply accepting it as the opposite of whatever an aesthetic experience up to our times should profess. More surprising and disappointing is the frequent ignorance of the important transformations of Kantian thought elaborated in the Critique of the Power of Judgment even by scholars who dialogue with his thought, starting perhaps from the prejudice that aesthetics is a negligible sectoral field, if not for some art lovers, but completely unusable when dealing with serious questions, as when discussing, for example, the quality or legitimacy of our forms of life ${ }^{5}$.

Desideri rightly states after a careful analysis of the «aesthetic movement from below» that characterizes Kant's reflection in the third Critique (Desideri [2011]: 187).

${ }^{4}$ In his extensive defense of the Enlightenment, Pagden (2013: 373-417) reviews, in the final chapter, some of the most prevalent positions of its «enemies».

${ }^{5}$ Just one example among many that could be given, taken from an author who has written books of great interest, Rahel Jaeggi, regarded as an exponent of the last generation of the Frankfurt School: «Can forms of life be criticized? Can we say whether particular forms of life are good, successful, or even rational? Since Kant it has been broadly accepted that happiness or the good life, in contrast to the morally right, cannot be determined philosophically. [...] The question of how we lead our lives has been consigned to the domain of unquestioned preferences or irreducible and unchallengeable identities. As with taste, there is no quarreling with forms of life.» (Jaeggi [2005]: 67 , italics mine). This is a surprising statement in many ways, starting with the fact that it is precisely taste that, in Kant's reflection, legitimizes the boundless field of what is susceptible to «quarreling», or discussion, as distinct, on the one hand, from what can be demonstrated under certain conditions - empirically and logically and, on the other, from mere individual, idiosyncratic prefer- 
As I hope to show, the critical philosophy inaugurated by Kant has valuable tools to offer to help understand our present, starting with the concept of "exemplarity» elaborated in the third Critique, in close relation to other notions, such as precisely that of «reflecting judgment» and «finality», but also of "heautonomy» and «common sense». It would be absurd, of course, to want to defend all the personal convictions that Kant shared with his time, many certainly indefensible. But personal convictions are one thing, thinking and understanding problems are another. The specialized studies on the notions just mentioned are endless, and there is no lack of very interesting studies from a philosophical-political point of view (see at least Arendt [1970], Ferrara [2008]). It is worthwhile, then, to try to clear the field of some misunderstandings surrounding some of these key notions, aiming to highlight the aspects that are most susceptible to further developments and applications. Here I will mostly follow the interpretative lines drawn by Emilio Garroni (especially [1986], [1992]), trying to compare them with some of those themes just mentioned, not yet on the agenda or in the foreground in the years when Garroni was writing.

\section{EXEMPLARITY}

«The expression "example" [...] had all the requisites to be destined to profoundly change the general orientation of critical philosophy» (Garroni [1992]: 142]. One of the places where the notion of example emerges most explicitly «in a strong Kantian sense» (ibid.: 25), is the fourth moment of the "Analytic of the Beautiful», there where Kant questions the modality of judgment of taste and of that peculiar feeling it expresses. The analysis of the modality proceeds in parallel with that of the quantity of the judgment of taste, dealt with in the second moment of the "Analytic»: the

ences. One need only read the pages of the "Dialectic of the Faculty of Judgment» to revisit such a trite view, or the important section 40 on "common sense» (Gemein$\operatorname{sinn})$, and the now extensive literature about it. kind of validity that demands a judgment of taste is, as is well known, an aesthetic, (inter)subjective universality, that demands to extend itself over the entire sphere of those who judge (and does not concern the logical extension of the concept). On the other hand, since the logical quantity of the judgment of taste is singular - insofar as ascribing the beauty to some object or all objects belonging to a class is a dead end because it would presuppose a conceptual principle for their subsumption -, it must only be exemplary. It is no coincidence that section 9 of the second moment (the peculiar universality of the judgment of taste) follows an argument similar to that made in section 21 of the fourth moment (devoted to its peculiar necessity), given the double implication between the exemplary universality and the exemplary necessity of the judgment. The necessity assigned by Kant to the judgment of taste is therefore also a «special kind» of necessity: not an apodictic necessity - neither theoretical nor practical - but precisely «only exemplary»:

Now this necessity is of a special kind: not a theoretical objective necessity, where it can be cognized a priori that everyone will feel this satisfaction in the object called beautiful by me, nor a practical necessity, whereby means of concepts of a pure will, serving as rules for freely acting beings, this satisfaction is a necessary consequence of an objective law and signifies nothing other than that one absolutely (without a further aim) ought to act in a certain way. Rather, as a necessity that is thought in an aesthetic judgment, it can only be called exemplary, i.e., a necessity of the assent of all to a judgment that is regarded as an example of a universal rule that one cannot produce (Kant [1790], \$18, 5:237).

This notion of exemplarity - the exemplification of a rule that cannot be made explicit, because it is indeterminate and can only be felt has struck many commentators. But it also happens to distinguished scholars (cf. Derrida [1978]) to appreciate the Kantian novelty, only to return to confuse some purely illustrative examples, with which Kant would like to facilitate, perhaps unhappily, the understanding of his arguments, 
with the exemplarity «in the strong sense» that - exemplifying a «rule that one cannot produce» - cannot determine anything, let alone a class of objects with certain characteristics, ornamental or not (cf. Velotti [2010]). Garroni's reading remains firmly anchored to this «strong» sense of exemplarity, not referable to the exemplification of determined concepts (this cat as a member of the class of cats) and referable, it would seem, to the example of an extraordinary person: the imitatio Christi certainly does not refer to an invitation to become a member of the class of Christs, but to Christ as «exemplum for human beings [...], that is, in the sense in which something concrete and determined is the bearer of a quality or condition that cannot be expressed otherwise than through its bearer» (Garroni [1992]: 90, note 76). This last clarification, given as a first approximation, could be misleading, however, like the one offered by Hannah Arendt in her reading of the Critique of the Power of Judgment. In fact, Arendt seems to assimilate exemplarity to particularly typical or emblematic empirical schemes:

The example is the particular that contains in itself, or is supposed to contain, a concept or a general rule. How, for instance, is one able to judge, to evaluate, an act as courageous? When judging, one says spontaneously, without any derivations from general rules, "This man has courage». If one were a Greek, one would have in "the depths of one's mind" the example of Achilles. Imagination is again necessary: one must have Achilles present even though he certainly is absent. If we say of somebody that he is good, we have in the back of our minds the example of Saint Francis or Jesus of Nazareth. The judgment has exemplary validity to the extent that the example is rightly chosen. Or, to take another instance: in the context of French history I can talk about Napoleon Bonaparte as a particular man; but the moment I speak about Bonapartism I have made an example of him. (Arendt [1970]: 84)

This interpretation of exemplarity leaves much to be desired and has been rightly criticized (Ferrara [2008]: 49-61; but see also Tavani [2010]
183 sg. $)^{6}$. Since Garroni's reference to the imitatio Christi could lead to a similar misunderstanding, it is good to clarify at least some points of the issue. Ferrara raises several objections to this reading, all of which are relevant, among which I mention: (a) the danger of assimilating examples to empirical schemata, and thus bringing exemplarity back into the realm of determining, rather than reflecting, power of judgment; (b) the risk of flattening the exemplary case to an image in its concreteness, however holistic, without grasping a «unity of purpose»; c) the difficulty in accounting for the possibility not only of selecting or «applying» an example - which obviously requires, like any judgment, the exercise of a reflecting, as well as determining power of judgment - but of creating a new one. Ferrara then proceeds to reconstruct a more adequate notion of exemplarity, reaching the following conclusion:

Examples orient us in our appraisal of the meaning of action not as schemata, but as well-formed works of art do: namely, as outstanding instances of congruency capable of educating our discernment by way of exposing us to selective instances of the feeling of the furtherance of our life. And the force of examples transcends local boundaries more easily than the force of laws or principles because they tap intuitions that run deeper, in the constitution of our subjectivity, than the level that requires translations. (Ferrara [2008]: 61)

But despite this reconstruction, perhaps it is necessary to insist on the fundamental issue: to Arendt's assertion that «The example is the particular that contains in itself, or is supposed to contain, a concept or a general rule», it should be immediately added that it is not just any rule, but that «rule that one cannot produce» $(\$ 18)$. The power of reflecting judgment, as Kant explains in section IV of the "Introduction» - as the power of applying aptly a rule to a given case, or as the power of finding a rule for one or more particu-

\footnotetext{
${ }^{6}$ The examples brought by Arendt seem, if anything, more assimilable to Vico's "poetic characters», perhaps not identical to the «fantastic universals» (Velotti [1995]).
} 
lars in order to classify them or to bring them together under the same universal law not yet given - certainly has a crucial epistemological value. And in all empirical judgments, cognitive or otherwise, the power of determining judgment (in which a universal or a rule is already given) and of reflecting judgment (in which a universal or a rule must be assigned "judiciously" or constructed because it is not available) must work together. However, the determining principle (Bestimmungsgrund) of the faculty of judgment in general is exemplarily exhibited in aesthetic judgments, if and when they are produced on the occasion of a (logically) singular judgment. And aesthetic judgments highlight, exemplarily, that our faculty of judgment in general cannot depend on a conceptual rule, nor does it necessarily have to rely on another rule or law that can be made explicit. Leaving all other considerations aside, this would lead to an infinite regress (the rule to apply the rule...). But it is precisely in aesthetic judgments that the universal to which the individual «thing», event or action is traced is what Kant calls a common sense or common feeling, a Gemeinsinn. And such a feeling escapes the problem of infinite regress in that it is «self-applicable» (Floyd [1998]: 195] or «self-congruent» (Ferrara [2008]). Yet, if such Gemeinsinn can only be felt (it is a Sinn, a sense as in "making sense", and it is a feeling, a Gefühl), it is at the same time a product of our cognitive faculties united in a «free schematism», where it is not a determined concept that is schematically exhibited but the same indeterminate legality or normativity of the whole intellect.

This is why Garroni can write that Kant «goes in search [...] of a condition that in a certain sense precedes the conditions - forms of intuition, pure concepts of the intellect, concept of freedom - already established in the first two Critiques, in that it is the most original condition of their very functioning in the territory of experience» (Garroni [1992]: 143). It will be necessary to return to the implications of a principle that is at the same time a sentiment detectable only exemplarily, and on the single "case» that triggers it, but not before having fine-tuned some impor- tant junctions on the concept of finality, since «the entire Critique of Judgment is [...] centered on formal finality» (ibid: 113).

\section{FINALITY AND FAVOR}

One of the objections raised by Ferrara, in the wake of Makkreel (1994), to Arendt's reading of exemplarity is of particular interest here: the risk of flattening the exemplary case to an image in its concreteness, however holistic, without grasping a «unity of purpose». The strength of the objection, it seems to me, lies not so much in the fact that the concrete case is an image (every image, in principle, could be exemplary under certain conditions and in certain cultural contexts), but precisely in the exemplary representation, in the singular case, of an indeterminate rule that is, subjectively, animated by a «unity of purpose». Indeed, on the one hand, there are those who have attempted to reformulate the disinterestedness required by aesthetic experience - as a suspension of any determinate, sensible or conceptual purpose - in psychological or cognitive terms of attention. Bence Nanay, for example, distinguishing between objects and their properties, lists four possible types of attention: «i. Distributed with regards to objects and focused with regards to properties; ii. Distributed with regards to objects and distributed with regards to properties; iii. Focused with regards to objects and focused with regards to properties iv. Focused with regards to objects and distributed with regards to properties» (Nanay [2016]: 24) ${ }^{7}$. The first is the most obvious form of attention, useful for classifying a multiplicity of objects possessing certain properties; the second would amount to wandering with the gaze, without dwelling on anything in particular; the third is of intense concentration on a specific purpose; and the fourth would come closest, according to Nanay, to describing an aesthetic experience, focusing on a single instance and yet letting one perceptually and imaginatively peruse

\footnotetext{
${ }^{7}$ For a more complex and adequate exploration of attention in relation to aesthetics cf. Desideri (2011: ch. 2).
} 
all its indefinite properties, without having already channeled them through conceptual purposes or immediate pragmatic needs. On the other hand, however, in the absence of a reflection on finality, the "umprompted eye» that Nanay associates with aesthetic experience will also have the virtue of defamiliarizing the world and its objects. Yet it is not clear why we should experience aesthetic pleasure, given that a defamiliarized world is also given in a psychotic or "alienated" experience. In order to give an aesthetic feeling of pleasure that depends above all on its determining principle (although accompanied, empirically, by feelings, desires and concepts of all kinds), defamiliarization is not sufficient. At the same time, it must be perceptible in its "unity of purpose», without being able to rely on a conceptually or pragmatically pre-established purpose. It is the famous «purposiveness without an end» or, precisely, «formal purposiveness», exposed by Kant in the third moment of the Analytic ( $\$ 10 \mathrm{ff}$.), dedicated to relation.

Even in this case, maintaining this Kantian perspective is not easy: on the one hand, there are those who try to naturalize finality as a result of evolution. It may be more heuristically convenient, from an adaptive point of view, to assume that reality is organized finalistically, even if this leads to errors and difficulties in accepting the very theory of evolution that assumes the emergence of this very attitude (cf. Guthrie [1993]; Girotto, Pievani, Vallortigara [2008]). On the other hand, an avowed atheist like Thomas Nagel has been critical of what he considers the neo-Darwinian "materialistic reductionism», hypothesizing instead a teleology of nature, even in dialogue with the supporters of the "intelligent design", without admitting, however, the assumption of a transcendent author (Nagel [2012]).

We could say that, in the first case, the assumption of a teleological organization of nature is considered a cognitive, subjectivistic bias, and, in the other, a realistic hypothesis about objective ends and values. Both perspectives ignore, however, the Kantian proposal of the third Critique that is, the most important and refined reflection that modern philosophy has produced on finality and teleology. The result is to preclude, in both cases, a perspective that avoids attributing purposes and values to reality, but neither confines them in a psychological subjectivity that would "project» them onto an indifferent and inert reality. The aesthetic principle elaborated by Kant - transcendental and not psychological - obviously does not say anything on the absolute ontological constitution of reality (final or non-final, sensible or senseless). But it allows to free all the contingency of empirical reality - which at any time could prove refractory or hostile to any form of sensible experience $^{8}$ - making it understandable, at least in its general lines, the organization of experience, and of the concomitant sphere of normativity, starting from our being already always immersed in it $^{9}$.

In Against Nature, Lorraine Daston (2019) summarizes all the reasonable objections raised in time by philosophers and anthropologists against the temptation to legitimize cultural norms and habits on the basis of a presumed correspondence with natural orders, but proposes a hypothesis on the origin of normativity in general (not of culturally specific and variable norms) from natural exemplars: "The human impulse to make nature meaningful is rooted in a double insight about order: normativity demands order; and nature

\footnotetext{
${ }^{8}$ «The reflecting power of judgment, therefore, can only give itself such a transcendental principle as a law, and cannot derive it from anywhere else (for then it would be the determining power of judgment), nor can it prescribe it to nature: for reflection on the laws of nature is directed by nature, and nature is not directed by the conditions under which we attempt to develop a concept of it which is in this sense entirely contingent» (Kant [1790] IV, 5:180). And, regarding genera and species: «For it may certainly be thought that [...] the specific diversity of the empirical laws of nature together with their effects might nevertheless be so great that it would be impossible for our understanding to discover in them an order which we can grasp, to divide its products into genera and species [...]» (ibid: V, 5:185).

${ }^{9}$ The need to reconstruct the genesis of judgment has been felt many times: two very different examples are Deleuze (1963) and Desideri (2011: 110 ff.).
} 
supplies exemplars of all conceivable orders», immediately adding that «natural order alone cannot dictate which specific norms to follow, if only because there are so many orders in nature» (Daston [2019]: 160). A consideration that seems inspired precisely by a Kantian perspective, which considers our encountering an order in nature we may add, human and non-human - as a kind of unexpected and contingent «favor» (Gunst, a word that recurs several times in crucial places in the third Critique). And if we add to the Kantian claim that the power of reflecting judgment is responsible for the ordering of entities in genera and species the important Kantian considerations on the use of analogy, then we would find a way to understand not only the emergence of different cultures from the different "orders» of nature, but their different ways of organizing the world symbolically. In fact, according to the Kantian distinction between inferring and thinking by analogy ${ }^{10}$, analogical inferences between entities are legitimized only for those properties that these entities can share to the extent that they belong to common genera and species (paritas rationis). Now, if the organization of entities into genera and spe-

\footnotetext{
${ }^{10}$ Analogy is often considered one of those terms that a "monological" modern culture would have removed from our legitimate ways of reasoning and operating, whilst it is a key term of Kant's third Critique. Here is a passage that illustrates Kant's distinction - in relation to analogy «in a qualitative sense» (an analogy of the predicates) between inferring and conceiving by analogy: «The principle that authorizes such an inference lies in the fact that we have the same reason to count animals, with respect to the determination in question, as members of the same genus with human beings, as humans, insofar as we compare them externally to each other, on the basis of their actions. There is par ratio. Similarly, in comparing the propositional products of the causality of the supreme cause of the world in the world with the works of art of human beings, I can conceive of the former in analogy to an understanding, but I cannot infer to this property in the cause of the world by means of analogy; for here the principle of the possibility of such an inference is precisely what is lacking, namely paritas rationis to count the supreme being as part of the same species along with human beings (with respect to their respective causalities)» (Kant [1790], note to $\$ 90,5: 464)$.
}

cies is different, then different analogical, contingent and defeasible inferences are also authorized, shaping more or less desirable forms of life, more or less adaptive or felicitous relations to nature. On this basis, there would be no need to advocate an «ontological pluralism» in order to take seriously cultures that are very different from the one to which we belong - with all the risks of sealing each culture within its own world, incommensurable with others - but to move the comparison on a symbolic level. Symbolism (Kant [1790]: $\$$ 59, 5: 351-352), as distinct from both the «objective schematism» (ibid.: $\$ 9,5: 218$ ) of knowledge and from merely "empty" thinking, is for Kant the level at which we "make sense» of our experience, at which the different forms of life, their exchanges, their transformations are then played out. And the distinction between nature and culture is also played out not on the basis of dogmatic ontologies, fixed one and for all within the boundaries of a certain culture, but from within the very organization of experience. We all agree that what we call nature and society, nature and culture, are intertwined, but is not precluding any distinction between the two - by assuming only an inextricable hybrid magma ${ }^{11}$ - a way of precluding the possibility of exercising a critique of specifically human (social, cultural, political) responsibilities in the face of, for example, the occurrence of natural disasters?

\section{NATURAL OR ARTIFICIAL?}

But if, on the basis of the "heautonomy» (Kant [1790]: V, 5:186; Floyd [1998]) of this aesthetic principle, the Kantian perspective allows us to understand why it is possible and necessary to renegotiate, plastically but not in a mere arbitrary way, the sensitive, cognitive and ethical grammar of different cultures, is this principle to be considered in turn natural or artificial? Or is it

\footnotetext{
${ }^{11}$ Needless to say, hybridization is a key word for Bruno Latour and his followers (e.g., Latour [1991]), who evoke it against the theoretical "purification» of the hybrids "perpetrated" by "the moderns".
} 
instead at this level, if anything, that an authentic «hybrid» is located ${ }^{12}$ ? This question has been extensively re-examined by Catherine Malabou (2014) in an essay entirely aimed at clarifying in what sense Kant understands in the first Critique the transcendental as the epigenesis of reason («a system of the epigenesis of pure reason», B 167), beginning with the famous section 27 of the Critique of Pure Reason, and finding its unfolding and fulfillment precisely in the third Critique. Malabou confronts at length some of Kant's major interpreters, none of whom offers, however, in her opinion, convincing answers ${ }^{13}$. The book is aimed at showing how attempts to "relinquish the transcendental», either through neurobiological reductionisms or through the anti-correlationism proposed by Quentin Meilassoux (2006) and taken up in various ways by supporters of speculative realism, are unsuccessful. A comparison with Malabou's important book would require a separate study, but here it is important to note the strong similarities with Garroni's reading on a fundamental point: Malabou considers the debate over whether the transcendental is natural or fabricated («factitious»), pointless, because it would be the very development of the transcendental, from the first to the third Critique to be epigenetic. Without specifically calling into question epigenesis in this context, Garroni is very clear on this point, and arrives at the conclusion that the faculty of judging is not even in all senses a faculty, since it is "self-constructed», investing with its character all the other faculties, and therefore the very status of the transcendental outlined in the previous critical works. For Garroni (and for Malabou, who on this issue arrives at almost literally identical

\footnotetext{
${ }^{12}$ Ferrara oddly assumes, perhaps in the wake of Gadamer's disputable interpretation, that Kant elaborates a «minimalist, naturalized concept of sensus communis» (Ferrara [2008]: ch. 2).

13 "The "system of the epigenesis of pure reason" implies an original co-implication of a priori and a posteriori, before and after, whose paradoxical complexity and meaning have not been clarified by any of the exegetical "keys" we have attempted so far» (Malabou [2014]: ch. 12).
}

conclusions $)^{14}$ it is not simply a matter of vaguely affirming, as Deleuze and Guattari do in the Introduction to What is Philosophy? (1991: 2), that "Kant's Critique of Judgment is an unrestrained work of old age, which his successors have still not caught up with», in which «all the mind's faculties overcome their limits, the very limits that Kant had so carefully laid down in the works of his prime», but to grasp the joints in which this revision of the transcendental is articulated. We could take as reference a section of the third Critique, which has always surprised the interpreters.

Kant, after having affirmed the exemplary necessity of the judgment of taste $(\$ 18)$ and after having provided almost a deduction of common sense (Gemeinsinn) as its principle, states in fact decisively that this principle «must be able to be assumed with good reason, and indeed without appeal to psychological observations, but rather as the necessary condition of the universal communicability of our cognition, which is assumed in every logic and every principle of cognitions that is not skeptical» (Kant [1790]: \$21, 5:239). Immediately afterwards, however, he seems almost to question the result just achieved, wondering "whether taste is an original and natural faculty, or only the idea of one that is yet to be acquired and is artificial» (Ibid.: $\$ 22,5: 240$ ). The question of the "natural and original», or instead "artificial and factitious» status of the principle of determination of judgment is "pointless», as Malabou argues, only if one goes in search of an exclusive answer: the answer that emerges from Garroni's reading is instead intimately paradoxical: the "nature» of the principle is said to be «in the making», «self-constructed» (Garroni [1992]: 210, 227), precisely because it is aimed at recognizing in that principle the condition of possibility of every culture. A condition that cannot be, circularly, only cultural, but not even only natural, as a guarantee of meaning that, making everything indistinctly sensible and justifiable, would not allow us to take seriously not only "other cultures",

\footnotetext{
${ }^{14}$ See the section on «The Backlash Effect of the Third Critique on the First» (Malabou [2014]: ch. 13).
} 
but not even our own. (Ibid.: 245-270). Making sense emerges, after all, as an aesthetical-ethical risk that we ought to run, without yearning for a «supreme meaning» or a triumph of a supposedly universal sense.

In conclusion, if we are really living in the ruins of modernity, I believe that it is neither a question of embalming them, nor of razing them to the ground, and that one of its main protagonists can offer precious resources to reshape that image of humanity that we feel is now inadequate in the face of the complexity of our forms of life, without the need to abandon ourselves to old and new longings for the absolute.

\section{REFERENCES}

Arendt, H., 1979: Lectures on Kant's Political Philosophy, ed. by R. Beiner, University of Chicago Press, Chicago 1992.

Consigliere, S., 2020: Favole del reincanto. Molteplicità, immaginario, rivoluzione, DeriveApprodi, Roma.

Daston, L., 2019: Against nature, MIT Press, Cambridge, MA.

Deleuze, G., 1963: La Philosophie critique de Kant, PUF, Paris.

Deleuze, G., 1983 : Pour en finir avec le jugement, in Id., Critique et Clinique, PUF, Paris, pp. 158169.

Deleuze, G., Guattari, F., 1991 : Qu'est-ce que la philosophie?, Les Éditions de Minuit, Paris.

Derrida, J., 1978 : La vérité en peinture, Flammarion, Paris.

Desideri, F., 2011: La percezione riflessa. Estetica e filosofia della mente, Cortina, Milano.

Elkins, J., 2003: What happened to Art Criticism?, Chicago University Press, Chicago.

Ferrara, A., 2008: The Force of the Example. Explorations in the Paradigm of Judgment, Columbia University Press, New York.

Floyd, J., 1998: Heautonomy: Kant on Reflective Judgment and Systematicity, in Parret, H. (ed.), Kants Ästhetik, de Gruyter, Berlin-New York, pp. 192-218.
Garroni, E., 1986: Senso e paradosso. L'estetica, filosofia non speciale, Laterza, Roma-Bari.

Garroni, E., 1992: Estetica. Uno sguardo-attraverso, Garzanti, Milano.

Girotto, V., Pievani, T., Vallortigara, G., 2008: Nati per credere. Perché il nostro cervello sembra predisposto a fraintendere la teoria di Darwin, Codice, Torino.

Graeber, D., 2015: Radical Alterity is just Another Way of Saying «Reality». A Reply to Eduardo Viveiros de Castro, "Hau: Journal of Ethnographic Theory" 5 (2), pp. 1-41.

Graeber, D., Wengrow, D., 2021: The Dawn of Everything. A New History of Humanity, Allen Lane, London.

Guthrie, S., 1993: Faces in the Clouds, Oxford University Press, New York.

Jaeggi, R., 2005: "No Individual Can Resist": Minima Moralia as Critique of Forms of Life, "Constellations" 12 (1), pp. 65-82.

Kant, I., 1790: Critique of the Power of Judgment, ed. by P. Guyer and E. Matthews, Cambridge University Press, Cambridge, 2013.

Latour, B., 1991: Nous navons jamais été modernes. Essai d'anthropologie symétrique, La Découverte, Paris.

Latour, B., 2004: Why Has Critique Run Out of Steam? From Matters of Fact to Matters of Concern, "Critical Inquiry" 30 (2), pp. 225-248.

Leghissa, G., 2021: Quanti Grubb ci sono davvero? Il discorso antropologico tra epistemologia e ontologia, "Aut Aut" 391, pp. 143-159.

Makkreel, R., 1994: Imagination and Interpretation in Kant: The Hermeneutical Import of the Critique of Judgment, University of Chicago Press, Chicago.

Malabou, C., 2014: Avant demain. Épigenèse et rationalité, PUF, Paris.

Meillassoux, Q., 2006: Après la finitude. Essai sur la nécessité de la contingence, Seuil, Paris.

Nagel, Th., 2012: Mind and Cosmos: Why the Materialist Neo-Darwinian Conception of Nature Is Almost Certainly False, Oxford University Press, New York.

Nanay, B., 2015: Aesthetics as Philosophy of Perception, Oxford University Press, Oxford. 
Pagden, A., 2013: The Enlightenment. And Why it Still Matters, Random House, New York.

Pinker, S., 2018: Enlightenment Now: The Case for Reason, Science, Humanism, and Progress, Penguin, New York.

Tavani, E., 2016: Hannah Arendt e lo spettacolo del mondo. Estetica e politica, manifestolibri, Roma.

Velotti, S, 1995: Sapienti e bestioni. Saggio sullignoranza, il sapere e la poesia in Giambattista Vico, Pratiche, Parma.

Velotti, S., 2010: Per un giudizio estetico «thick». Steinberg, Johns e l'arte contemporanea, "Paradigmi” 28 (2), pp. 67-85. 